\title{
Research on Domestic and Foreign Inclusive Growth
}

\author{
Chongmei Wang \\ Shandong institute of business and technology, Yantai, China \\ Worshipmei7654@163.com
}

\begin{abstract}
The cooperation and synergetic development is of great strategic significance for expanding the economic hinterland of Shandong and revitalizing the economy in Liaoning, which also opens up the idea for the two provinces to implement the Belt and Road construction. Based on the inclusiveness, the idea of prior synergistic development in the two peninsula subregions of Shandong and Liaodong is emphasized to promote Shandong peninsula urban agglomerations and mid-southern Liaoning urban agglomerations to the national strategy. It applied the regional spatial spillover effect and regional association effect model to analyze the synergetic development mechanism of urban agglomeration, determine its control parameters and order parameters, and evaluate the degree of regional synergetic development, and further provided the path and policy for the synergetic development of Pan-Bohai subregional urban agglomeration.
\end{abstract}

Keywords-Inclusive growth; Synergetic development; Regional space integration; Ecological civilization

\section{INTRODUCTION}

Inclusive growth is an important value orientation of economic and social coordinated development in China's Twelfth Five-Year Plan. The core idea of "sharing" will accelerate the transformation of China's economic growth mode and pay more attention to green growth, balanced growth, just growth and overall growth.

In the post-economic crisis era, the focus of world economic development has shifted to the Asia-Pacific region, especially Pan-Bohai Area, the center of Northeast Asia. The State Council takes the synergetic development of Beijing, Tianjin and Hebei as a major national strategy, which provides a significant historical opportunity for the development in PanBohai Area. Although the economic development situation in Shandong is slightly better, the economic hinterland is small, so it needs to strengthen economic cooperation with Liaoning and northeast region; on the other hand, as an old industrial base the country has an urgent need to revitalize, Liaoning has poor economic competitiveness, so it also needs to strengthen economic cooperation with Shandong to introduce external forces to activate the local economy. According to the strategic spirit of President Xi Jinping's Belt and Road initiative, the synergetic development of Pan-Bohai Area will connect the Yangtze River Delta and the Pearl River Delta into a smooth "Golden Edge".

\section{BASIS OF SYNERGETIC DEVELOPMENT BETWEEN SHANDONG PENINSULA AND LIAONING PENINSULA}

Shandong Peninsula and Liaoning Peninsula belong to different administrative subjects, and affected by administrative, geographical, environmental and traffic factors, they lack of an all-round synergetic development mechanism and institutional design and arrangements, difficult to ensure stable and normal cooperation. In recent years, the discussion of economic growth around the club convergence hypothesis has become the forefront of economic research. Regional space integration is an important part of strategic adjustment by countries and regions today, which is also an effective way to strengthen regional cooperation and enhance regional competitiveness under the new situation. Therefore, based on the inclusiveness, the prior synergistic development of sub-regional urban agglomerations - Shandong Peninsula and Liaoning Peninsula, is conducive to promoting the establishment and sustainable development of Bohai Economic Rim.

\section{CONNOTATION OF INCLUSIVE GROWTH}

At present, the academic community has not a unified definition of inclusive growth, and many scholars studied inclusive growth from different perspectives [1]. The formation of the concept of inclusive growth is closely related to the theory of right poverty developed in the $1980 \mathrm{~s}$, but the systematic study of inclusive growth began after the Asian Development Bank proposed the concept of inclusive growth in 2007 [2]. It emphasizes the coordinated development of economy and society, advocates equal opportunities, and strives to make all people enjoy the fruits of economic development. In 2008, the World Bank defined inclusiveness as a process that covers equity, equality of opportunity, protection of market and career transformation. After the World Bank and Asian Development Bank defined the inclusive growth, some foreign scholars have begun to focus on inclusive growth research. Conceicao, Gibson, Heitor and Sirilli (2001) argued that inclusive growth is a process of development involving every citizen in all countries; Chatterjee (2005) defined inclusive growth as a process of broad participation and commitment to reducing poverty and social exclusion. Ali et al. (2007) defined inclusive growth as propoor growth in social opportunity [3]. Rauniyar and Kanbur (2010) integrated the research results of the Asian Development Bank and defined inclusive growth as unequally decreasing growth [4-6]. Regions will move toward cooperation, and this idea comes from the principle specified in Communist Manifesto by Marx and Engels that as the 
bourgeoisie opens up the world market, the world economy is bound to be interdependent. The earliest theoretical discussion of regional economic cooperation was Adam Smith (1977), who proposed the theory of regional division of labor based on absolute dominance from the perspective of regional division of international trade. In the $1940 \mathrm{~s}$, due to the influence of Keynesian theory, the theory of regional economic cooperation based on state interventionism appeared. After the 1990s, the urban belt theory of French economic geographer Gottman and the theory and practice of Japanese metropolitan area set off the research of regional economics and promoted the development of regional economic practice in China.

\section{RESEARCH DEVELOPMENT INCLUSIVE GROWTH}

The Chinese research results of inclusive growth were mainly concentrated around 2010, which focused on economic reform, macroeconomic management and sustainable development. Cai Rongxin (2009) described inclusive growth as friendly growth for the poor. Du Zhixiong (2011) argued that inclusive growth is a kind of development concept and theoretical system which can benefit all the people through the promotion and guarantee of equality of opportunity in the process of economic growth. Feng Haibo (2010) argued that inclusive growth emphasizes social equity on the basis of necessary economic growth rate and helps China overcome the "income trap", which is the inevitable choice for China to realize economic development, political stability and social harmony. Li Gang (2011) argued that the policy objective of inclusive growth is mainly to achieve harmonious and equal development between people, equitable development between generations and elimination of other economic and social problems in the process of economic growth [7]. Mei Weixia (2011) argued that polarization between the rich and the poor has become the biggest embarrassment of economic development, and because the Pareto effect of reform ceases to exist due to the exclusive growth pattern of development, the Matthew effect of wealth distribution makes the reform increasingly deviate from the goal of common prosperity. Therefore, the public nature of government policy needs to be rebuilt to improve the social security network, achieve inclusive growth and establish the wealth-sharing society. Guo Han et al. (2011) from the perspective of harmonious interests in the decentralization system discussed how China achieves inclusive growth from exclusive growth [8-9]. Wei Jie (2011) based on the fuzzy comprehensive evaluation method of membership degree investigated and measured the inclusiveness of China's economic growth from 1978 to 2009 and found that the inclusiveness of economic growth in the past 30 years is not inspiring. Ge Xiaoru (2011) argued that inclusive growth emphasizes economic growth - coordination and inclusiveness between ecological environment and people. Fan Yilin and Wu Xiaobo (2011) argued that social exclusion theory is the theoretical basis of inclusive growth. Gao Chuansheng (2012) believed that inclusive growth is a new development idea and model of China in the new era and emphasized the responsibility of subjects, coordination of development contents, equality of opportunities in the development process, and benefit sharing of development results [10].

\section{APPLICATION RESEARCH OF INCLUSIVE GROWTH}

Zhu Zhiyong (2011) believed that the process of inclusive growth is the process of reasonable game playing and balanced realization of interests of government, enterprises and labors. Ye Hang (2011) argued that the design of the exclusive mechanism must be adapted to the goal of inclusive growth and equalization of basic public services, the exclusive mechanism of quasi-public goods should be reconstructed, and different exclusive mechanisms should be designed based on the public nature and exclusiveness of such goods, and the impact of inequality in the process of consumption on individual effect, economic growth and social stability so as to abandon the original non-balanced development strategy from the root and optimize the structure of fiscal expenditure. Fang Yong et al. (2012 from an open perspective believed that inclusive growth is mainly reflected in the promotion of trade and investment liberalization, opposition to investment and trade protectionism, and the perseverance and practice of idea of inclusive growth is the strategic orientation of China to further enhance the level of open economic development [11]. Zhu Chuangeng et al. (2012) pointed out that it requires multiple conditions to achieve regional synergetic development, including geospatial proximity, cultural similarity, similarity or complementarity of resources, and industry isomorphism [12]. Gao Youcai (2013) argued that one of the essentials of inclusive growth is the obligation of developed regions to help economically underdeveloped areas achieve economic growth. As long as the interregional market system is not perfect, factor resource flow is not smooth and regional industrial competitiveness cannot be improved, the regional economic development gap may be further expanded; to narrow the gap, inclusive growth should become an aspect of balanced industrial development. He selected the Central Plains Economic Zone as the research object to analyze the specific path for Central Plains Economic Zone to achieve inclusive growth from balanced industrial development, regional balanced development, and rational use of resources [13-14]. Zhou Liqun (2014) pointed out that the synergetic development cannot take the old road that competition is greater than cooperation but should take a new road to meet modern industrial division of labor and complementary regional advantages [15].

Although domestic and foreign scholars have extensively studied the theory of inclusive growth, the definition of inclusive growth has not been interpreted uniformly so far. There is no uniform indicator or method for inclusiveness measure. There is little literature to apply the inclusive theory to the study of interregional coordinated development. Inclusive strategy has some achievements, but it is the future research direction of inclusive governance that promotes economic growth and regional development. The existing research on the synergetic development of regional economy focuses on the coordination of differences in regional economic development, interregional transfer of industry, formation and development of industrial clusters, and regional and interregional synergetic development, mainly describes the idea and trend of synergetic development of regional economy as well as literature on regional synergetic development, and carries out studies from the perspective of competition, cooperation, influencing factors, evaluation and dynamic 
mechanism. But the internal mechanism and operation mechanism of synergetic development of regional economy are still in the exploratory stage, and few scholars applied inclusive growth to the practice research on the synergetic development of Pan-Baohai sub-regional urban agglomeration.

The discussion on economic growth around the regional economic growth convergence hypothesis has become a cutting-edge issue in economic research. However, there is less research that applies neoclassical economics, new economic geography, spatial economics and spatial econometrics as well as spatial convergence club that considers spatial association. This study holds that the essential connotation of inclusive growth emphasizes participation, sharing and comprehensive coordination, that is, how to coordinate the relationship between various factors so as to promote social progress, and equity, politics, society, economy, humanities, environment and other factors need to be considered. It is an important pillar to change the way of economic development in China. This paper studied the theoretical basis for inclusiveness of synergetic development of Pan-Bohai sub-regional urban agglomeration, defined the connotation of inclusive growth and constructed the inclusiveness dimension of synergetic development. It applied the regional spatial spillover effect and regional association effect model to analyze the synergetic development mechanism of urban agglomeration, determine its control parameters and order parameters, and evaluate the degree of regional synergetic development, and further provided the path and policy for the synergetic development of Pan-Bohai sub-regional urban agglomeration.

\section{ACKNOWLEDGEMENT}

This work was financially supported by the Soft Science in Shandong (5002-001-030833).and Shandong Social Science Planning Project (P2017103014482048).

\section{REFERENCES}

[1] Ali, Ifzal. "Pro-poor to Inclusive Growth: Asian Prescriptions". ERD Policy Brief Series, 48, Asian Development Bank. 2007.

[2] Ali, I, Zhuang J. Inclusive Growth toward a Prosperous Asia: Policy Implications. ERD Working Paper No.97, Economic and Research Department, Asian Development Bank. 2007.

[3] The World Bank. "What is inclusive growth-PRMED knowledge brief". 2009.

[4] Chatterjee. Poverty Reduction Strategies-Lessons from the Asian and Pacific Region on Inclusive Development. Asian Development Review. 2005.

[5] Anselin L. Spatial Econometrics: Methods and Models, Dordrecht: Kluwer Academic Publishers, 1988.

[6] Anselin, L., Spatial Externalities, Spatial Multiliers and Spatial Econometrics, International Regional Science Review, 2003(26), 153166.

[7] Li Gang. "Academic Basis, Theoretical Framework and Policy Direction of Inclusive Growth [J]. Economist, 2011 (7). Edgar M. Hoover: "Introduction to Regional Economics" Commercial Press, 1990.

[8] Goh Chok Tong. Research on Economic Thought. World Economy, 1995 (9): 21-23.

[9] Zhang Haohan, Meng Jing. New Pattern of Development of Yangtze River Delta Metropolitan Area - Functional Change and Space Integration of Nanjing Metropolitan Area. Social Sciences in Nanjing, 2007 (9): 10-14.

[10] Qin Chenglin, Zhang Weili, Regional Economic Growth Club Convergence Review, Economic Perspectives, 2008 (3).

[11] Zhu Chuangeng, Qiu Fangdao, Meng Zhaoyi. Coordinated Development of Provincial Border Region. Science Press, 2012.

[12] Liu Yingxia. Spatial Spillover, Spatial Club Convergence and China's Regional Economic Growth, China Social Sciences Press, 2013.

[13] Heckman Harken: Synergetics, Shanghai Translation Publishing House, 2013.

[14] Zeng Kunsheng. Dynamic and Coordinated Development of Regional Economy [J]. China Soft Science, 2000, (4). 